\title{
A DIMENSÃO ESQUECIDA: a questão da agência no trabalho do corte da cana de açúcar
}

\author{
Jaime Santos Júnior*
}

\begin{abstract}
Ao fixar o interesse analítico nos elos que unem a experiência do trabalho e os processos constitutivos de identidades, a pesquisa buscou flagrar as pequenas, mas subjetivamente importantes formas de mediação e cálculo envolvidos nas estratégias de ação de trabalhadores do corte da cana de açúcar. Os resultados sugerem que, conquanto o traço saliente desse contexto seja o da precariedade, os significados atribuídos ao trabalho deixam entrever as fissuras que denotam a capacidade de agência dos indivíduos na condução das suas vidas, distante de uma imagem que os toma como meros espectadores da história.
\end{abstract}

Palavras-chave: Trabalho. Identidades. Agência. Setor sucroalcooleiro. Sergipe.

\section{APRESENTAÇÃO' 1}

Com presença marcante no cenário do trabalho no universo rural, a colheita de cana de açúcar movimenta um amplo e variado mercado de trabalho. A existência de acordos entre empresários do setor e usinas que preveem o fim das queimadas trazem à tona o destino de milhões de trabalhadores que são requisitados a cada safra. Ao mesmo tempo, evocar as situações em que se executa esse tipo de atividade, cingida pelo signo do "precário", recoloca a questão sobre se é possível conciliar as exigências pelo aumento da produtividade com a saúde do trabalhador.

O volume de mão de obra empregada, na comparação com outros setores agrícolas, apresenta algo em torno de $74 \%$ de vínculos

\footnotetext{
* Universidade Federal do ABC (UFABC). Programa de Pós-graduação em Ciências Humanas e Sociais. Av. dos Estados, 5001. Cep: 09210-580. Bangu - Santo André - São Paulo - Brasil. jaimesjr.22@gmail.com

${ }^{1}$ Este texto teve uma versão inicial que foi apresentada no $38^{\circ}$ Encontro Anual da Anpocs, em 2014, no GT21 - Metamorfoses do Rural Contemporâneo. As críticas colhidas naquela ocasião, bem como as que incorporei para esta versão, advindas das sugestões feitas pelos pareceristas desta revista, me permitiram calibrar melhor o que pretendo argumentar. Fica o registro de agradecimento.
}

formais (Moraes, 2011), cuja modalidade é o contrato por safra. ${ }^{2}$ A necessidade de aumentar a possibilidade de estabelecer vínculos, talvez refeitos a cada safra, impele os trabalhadores à circulação entre as diferentes regiões produtoras, o que acaba por criar a situação atípica do "emprego recorrente", tão bem capturada por Silva (1992) no sintagma do "permanentemente temporário". Tal fato cria outra diferença com relação aos estudos sobre mercado de trabalho em contextos urbanos, onde a figura do "desemprego recorrente" atinge diferenciadamente os indivíduos e marca o compasso das trajetórias ocupacionais para algumas categorias. ${ }^{3}$

O que me proponho a fazer, neste texto, é arguir sobre o modo como os cortadores de cana pensam sua vida na relação com um tipo de trabalho que possui essas características. Persigo a hipótese de que a estrutura de oportunidade e constrangimentos em que são tomadas as decisões ordinárias sobre a gestão

2 Firmado por prazo determinado, pela natureza e transitoriedade que justificam a predeterminação do prazo, como determina o art. 443 , $\S 2^{\circ}$, letra “a”, da CLT, o art. 19 do Decreto $n^{\circ} 73.626 / 79$ segundo os quais o safrista é todo trabalhador que se obriga à prestação de serviços mediante contrato por safra.

${ }^{3}$ Sobre isso, ver, por exemplo, Guimarães (2002, 2017). 
da vida nesse contexto deixa entrever diferentes "estilos de reflexividade" (Archer, 2003), que dão sentido às trajetórias.

Desenvolvimentos recentes no âmbito da teoria social, nos quais me ancoro, refletem o interesse pela compreensão desses agenciamentos, naquilo que Alexander (1987) bem definiu como "o novo movimento teórico". Nesse sentido, é um tipo de análise que não se presta a individualizar comportamentos típicos para ilustrar normas ou modelos, mas que se propõe a descobrir mecanismos que permitam explicar a diferenciação nas formas de engajamento, a trama das resistências miúdas, ou ainda a maneira como se atribuem significados às trajetórias de trabalho. Esse lugar analítico, em que confluem constrangimentos e competência agêntica dos sujeitos na (re) produção das estruturas sociais, vem ocupando o noticiário das ideias, malgrado as diferenças, em estudos tais como os de Coleman (1987), Giddens (1979), Archer (2007), entre outros.

O questionamento de uma filosofia do sujeito que, por muito tempo, trabalhou com uma visão homogeneizadora do homem em sociedade, supunha uma sorte de unidade fundamental, de um "eu coerente", e ensejou uma promissora agenda de pesquisa sensível à admissão da multiplicidade das experiências vividas (Turner et al., 2016). Para o caso dos estudos sobre o trabalho, a ampliação do interesse em aspectos até então considerados de menor valor, tais como a família, o cotidiano, o lazer, para citar os mais palpitantes, que estabelecem novas zonas de comunalidade, formas de engajamento e clivagens, embaralhou as cartas $\dot{0}$ em um cenário que deixou de hierarquizar as práticas dos trabalhadores como indicadores i de maior ou menor nível de "consciência".

É nesse sentido que as ambivalências possíveis entre práticas e representações do trabalho desvelam um lugar analítico para se pensar a questão da agência. Parece contraintuitivo supor que o elevado constrangimento do contexto, que aparentemente reduz a margem de atuação dos sujeitos, possa servir de convite para que atentemos às nuances presentes nas ações cotidianas. Tanto mais porque sabemos como a noção de "precariedade" se torna um preâmbulo tentador para elucidar as situações de trabalho no corte de cana e, por via de consequência, as ações dos trabalhadores. A exposição à insalubridade do tempo, as exigências (cada vez maiores) de produtividade, os casos de morte por exaustão e, não raro, de flagrantes de trabalhadores em condições análogas à escravidão reforçam essa chave de leitura. Não é por acaso que os últimos vinte anos registraram um acúmulo de pesquisas com questões que gravitam em torno das condições que tornam esse tipo de trabalho precário (Alves, 2008; Novaes, 2007; Silva, 1999; Thomaz Jr., 2002). Mais recentemente, com o aumento da mecanização da colheita e inovações tecnológicas no processo produtivo do açúcar e do álcool, outras mudanças têm atraído a atenção dos pesquisadores, tais como a reconfiguração de um mercado de trabalho que se nutre, em ampla escala, da movimentação de trabalhadores vindos de outras regiões, especialmente do Norte e Nordeste (Menezes, 2002; Silva, 2008).

No entanto, importará aqui compreender a precariedade não como um postulado, mas tomá-la a partir das matrizes discursivas que revelam as maneiras pelas quais os trabalhadores pensam suas vidas. Por essa razão, reduzir o foco para analisar a competência cognitiva e reflexiva dos sujeitos em suas práticas cotidianas é querer compreender como são estabelecidos os "parâmetros para julgamentos" (Boltanski; Thévenot, 1991).

Decantar os significados atribuídos pelos próprios sujeitos a partir das imagens que são construídas sobre o trabalho no corte de cana, como via de acesso para se chegar à complexa trama em que mecanismos de decisão, formas de engajamento, pequenos cálculos e uma gramática muito particular nos modos de se referir ao trabalho, são indícios de diferentes manifestações de reflexividade. ${ }^{4}$

${ }^{4}$ Uso o conceito de reflexividade no sentido em que Ar- 
Para ir direto ao ponto, se for verdade que as condições estruturais que organizam esse tipo de trabalho definem e limitam o horizonte do possível, a maneira de agir dos que nele atuam, é igualmente válido perscrutar o outro lado, ou seja, o modo como o homem vivencia, experimenta, ${ }^{5}$ e interpreta essa limitação. Há, nesse sentido, um suposto que norteia meu argumento: alinho-me àquelas abordagens para as quais o cotidiano, o ordinário, manifesto tanto nas ações como nas práticas e configurações discursivas dos indivíduos, não se reduz ao anedótico, ou ao que deve ser lido como epifenômeno (Certeau, 2014; Pais, 2003).

Em termos sociológicos, sublinhar a importância da agência significa considerar que as práticas sociais são, antes, o reflexo sempre instável e contingente da maneira como os indivíduos interpretam as orientações normativas que derivam do quadro social mais amplo em que estão inseridos. Nesse sentido, sou tributário de estudos pioneiros sobre o trabalho nos canaviais, a exemplo de Sigaud (1979), Garcia Jr. (1989), Lopes (1978), Silva (1999) e Menezes (2002), que aplainaram o caminho e forneceram pistas sobre as diferentes facetas que podem assumir as representações da precariedade das condições de vida desses trabalhadores, o que me conduziu à pluralidade de significados contidos nas mais diversas ações de resistência cotidiana. Não se quer, aqui, discutir erros ou acertos dessas interpretações, pelo risco do anacronismo, mas retomar a problemática apresentada por eles, formulando novas questões.

\section{CAMINHOS DA PESQUISA EM SERGIPE, BRASIL}

Em contextos como o do trabalho no corte da cana de açúcar, onde o valor de face

cher (2012, p. 2) define: "reflexivity is defined as the regular exercise of the mental ability, shared by all normal people, to consider themselves in relation to their (social) contexts and vice versa".

${ }^{5}$ Emprego a noção de experiência tal como é definida por Thompson (1981). dos fenômenos, ou o traço da precariedade, salta a olhos vistos, a primeira condição que se impôs foi a de resistir a essa constatação imediata, na maioria das vezes lastreada no universo simbólico do pesquisador. Em termos metodológicos, essa abordagem é a mesma que sugere Ortner (1995), em artigo seminal, ao argumentar que muitos entre os mais influentes estudos sobre resistência são drasticamente limitados pela falta de perspectiva etnográfica (ethnographic refusal). Assim, ela afirma que a inversão de perspectiva, observando os sistemas de baixo para cima (Ortner, 1995), tem como corolário priorizar não a dimensão da "dominação", da "exploração", da "espoliação", mas, ao contrário, mobilizar elementos que escapem das categorizações simplistas e menosprezem a perspectiva dos que, por vezes, estão nas franjas das tipologias clássicas. ${ }^{6}$ No mesmo sentido, Fonseca (2006, p. 2) acrescenta que o que se recusa é a "alegação de que não existe nada mais nativo que não seja explicado pela influência das forças dominantes" (ou, se existe, certamente não é digno da atenção dos pesquisadores).

Para dar consequência a essa proposta, a pesquisa ${ }^{7}$ teve lugar entre os anos de 2011 e 2013, e o estudo de campo focalizou o Estado de Sergipe. Trata-se de uma área canavieira que, a despeito de estar integrada ao setor sucroenergético nacional, não está entre os grandes estados produtores. Qual o interesse, então, de observar o panorama a partir de um caso relativamente marginal? O primeiro elemento que merece destaque é a pouca literatura disponível sobre a indústria canavieira sergipana, que focalize os últimos cinquenta anos, visto que ela é vasta quando se refere ao período antecedente, especialmente sobre os oitocentos (Almeida, 1993; Passos Sobrinho,

${ }^{6}$ Não por acaso, Lahire (2001) lembra que muitos pesquisadores se frustram ao não encontrarem os "verdadeiros operários", "verdadeiros quadros", "verdadeiros artesãos”, acreditando que o problema é metodológico. Nem de longe isso é o mesmo que recusar construções ideais típicas, mas sublinhar o fato de que os atores podem não apresentar todas as características do molde.

${ }^{7}$ Ver: Santos Jr. (2017). 
1983). No entanto, e para dar maior densidade ao recorte empírico da pesquisa, apoio-me em outra justificativa. O estado de Sergipe se constitui num rico veio de possibilidades para que se possam recolocar questões até aqui analisadas, tendo em vista a realidade dos grandes centros produtores; ele permite, assim, perseguir as novas dinâmicas ora em curso nas zonas de expansão, num cenário de retomada da produção. ${ }^{8}$

Isso implicou enfrentar uma nova agenda de análise, que requeria atenção sobre como os circuitos migratórios se reconfiguravam

Mapa 1 - Distribuição da área plantada de cana em Sergipe

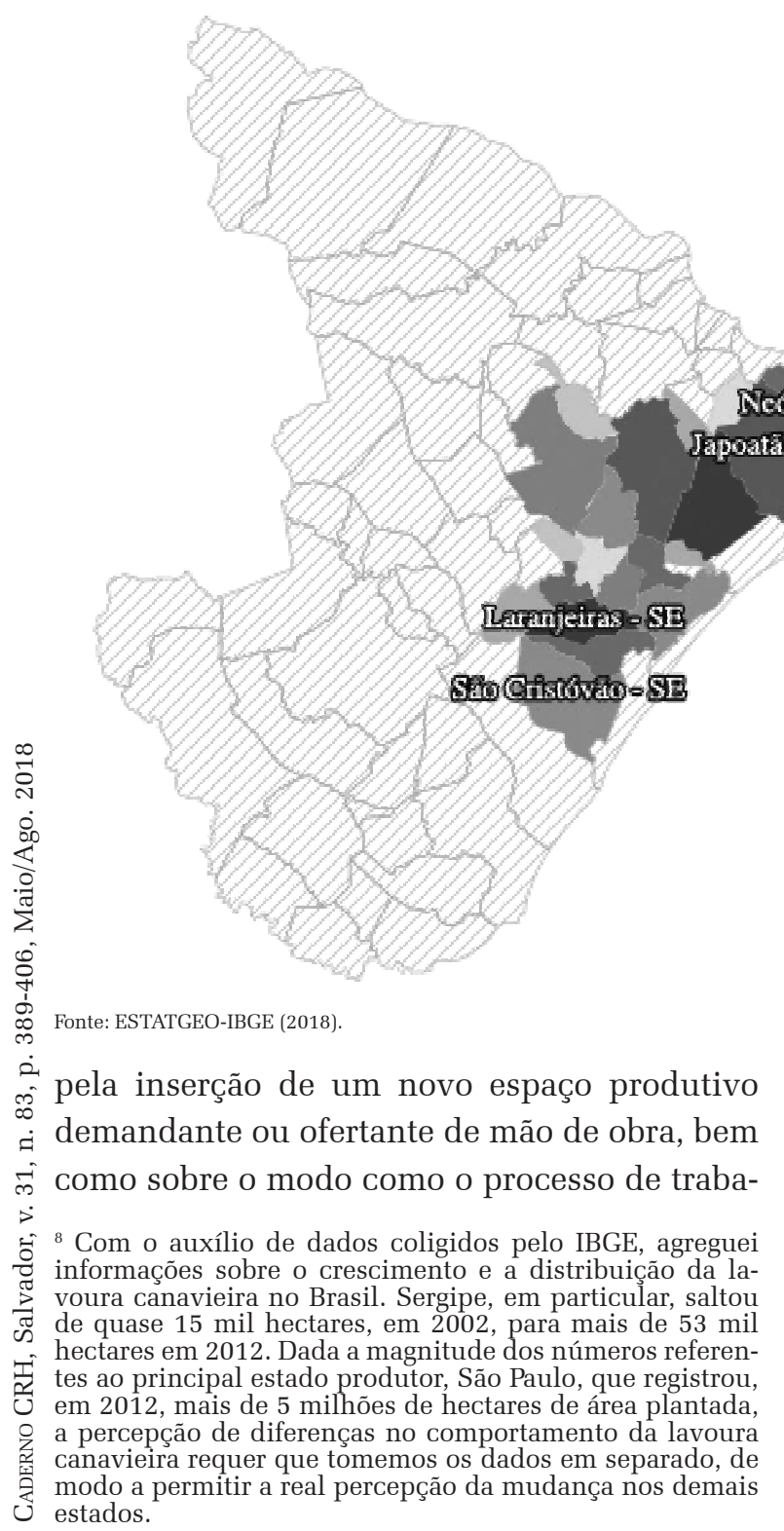

lho se relacionava com a questão da mecanização, a intensidade da jornada, o perfil da mão de obra empregada, as formas de resistência e conflito que ali vicejavam e, sobretudo, a maneira como os trabalhadores que ali estavam entendiam o universo que os circundava. A distribuição espacial das usinas no Estado de Sergipe revela sua grande concentração na região do Vale do Cotinguiba. Ali se localizam as seis usinas existentes.

Na composição da amostra dos casos, foram entrevistados trabalhadores das seis usinas presentes no estado, num total de trinta entrevistas. ${ }^{9}$ Em razão do elevado grau de circulação dos cortadores entre as usinas, pareceu-me ser melhor critério, para a seleção dos casos, o grau em que variava essa circulação, e não meramente a seleção em razão dos locais de trabalho, já que a gestão do trabalho e o porte das usinas não apresentaram diferenças significativas que justificassem essa última opção, ao menos não na área investigada. Assim, a amostra foi composta com os seguintes perfis:

Em razão da rotatividade entre as diferentes usinas:

- Indivíduos que trabalharam em apenas uma ou mais de uma usina existente no estado.

- Migrantes de outros estados: os que vivem em alojamentos (majoritariamente alagoanos e baianos).

- Sergipanos que possuíam experiência de migração: via de regra, São Paulo é o destino.

Também fiz variar os locais de residên-

${ }^{9}$ As entrevistas foram realizadas, em sua maioria, nos locais de residência dos trabalhadores, em alojamentos nas usinas. Em outros casos, realizei conversas informais nos locais de trabalho (no eito) e em momentos de lazer com grupos de trabalhadores dos quais fui convidado a participar. O compasso desse registro, em perspectiva etnográfica, mostrou-se fundamental para recompor elementos do cotidiano, das práticas sociais, das relações com a família e na comunidade, entre outros aspectos. 
cia. Por essa via, descobri circuitos migratórios diversos, nem sempre coincidentes. Se o destino dos cortadores sergipanos, entre os entrevistados, é São Paulo, os circuitos não são os mesmos. Isso também é válido para os circuitos migratórios de sertanejos baianos e alagoanos, que se deslocam para as usinas sergipanas. Através desses últimos, cheguei a outros circuitos migratórios para o Sudeste.

A ausência de mulheres no corte da cana em Sergipe, ao que pude constatar, sugere que elas são aproveitadas em outras fases do processo produtivo. Em geral, estão no plantio e nos chamados "tratos culturais". ${ }^{10}$ Portanto, a seleção dos casos deu-se prioritariamente entre trabalhadores que estão no corte da cana.

Lembro ainda que os excertos de entrevistas que apresento a seguir não devem ser lidos como casos paradigmáticos, pois o intuito foi o de trazer exemplos de configurações discursivas que reúnem aspectos também presentes em outras falas. Nesse sentido, e isso importa metodologicamente, não é o somatório de casos que empresta força ao argumento aqui sugerido, tanto mais porque não dirigi o foco para a construção de tipologias como demarcadores de identidades, como meros instrumentos para, de novo, reencontrar um sujeito genérico (analiticamente típico) a partir das narrativas contingentes e singulares de meus entrevistados. Os discursos encontraram um ponto de saturação à luz das variáveis que se mostraram decisivas em campo, e dos critérios previamente elencados. Essa foi a métrica encontrada para flagrar diferentes falas e os efeitos da influência do contexto e das experiências de vida no modo como se constroem identidades. Vejamos, a seguir, como isso se apresenta.

\section{O CONTEÚDO DO VIVIDO E A ME- DIAÇÃO DO ATOR}

A expressão que mais ouvi durante as entrevistas foi: "Cortar cana é um serviço pe-

${ }^{10}$ Preparação do solo para o plantio. sado”. É quase impossível não se deparar com esse relato quando se trata das condições de trabalho no corte da cana. Ainda que variassem as experiências de trabalho em diferentes usinas, inclusive entre os que migram para outros estados, a maneira de qualificar o trabalho no corte da cana permanece invariável. O truísmo da afirmação inicial fornece a magnitude da evidência imediata, aquela que se apresenta a qualquer pesquisador que queira adentrar nesse tema. Por certo, estamos falando de um tipo de trabalho que se situa entre os mais degradantes à saúde dos trabalhadores. No entanto, o leque de significados atribuídos ao trabalho não se esgota com essa afirmação. Ou melhor, não me parece factível considerar que um mecanismo alheio às vontades individuais seja a mola propulsora que os condena a uma situação de vida e trabalho expressa na metáfora do "cativeiro".

É possível distender esse argumento quando observamos, por exemplo, a vida pregressa dos trabalhadores entrevistados. Os achados de outros pesquisadores, no tocante à vida pregressa dos trabalhadores do eito, mostram que as respostas tendem a ser convergentes quanto à origem familiar (Menezes, 2002; Silva, 1999; Woortmann, 1990). Oriundos de famílias de pequenos produtores rurais, por vezes ex-funcionários dos antigos engenhos da região, os trabalhadores entrevistados foram socializados em um ambiente onde a atividade na roça era parte integrante de suas tarefas diárias. No contraponto, a escola surge como algo distante, fora do ideário em que foram criados. Os conhecimentos ali fornecidos são para outra realidade. Sendo assim, na maioria dos casos, o início prematuro nas atividades de trabalho no campo foi a regra encontrada.

Entrevistador - Conte-me sobre o que faziam seus pais. Onde viviam? Em que trabalhavam?

- Meus pais trabalhavam numa usina que tinha aí embaixo. Fechou já. Engenho das Pedras. Ele trabalhava com cana, negócio de cana: plantação, cortar. Aí, muitos tempos, fechou. Tem na faixa de uns trinta a quarenta anos que fechou. Depois, ele co- 
meçou a trabalhar de vaqueiro, essas coisas. E eu já trabalhava, chamava boi, pastorava boi mais eles. Depois fiquei nessas usinas. Fui pro Proveito, Santa Clara, Vassouras [nomes de antigas usinas]. Já trabalhei nessas usinas todas. Comecei a trabalhar com doze anos de idade e disso para cá não parei ainda (Romeu, ${ }^{11} 59$ anos).

Entrevistador - Conte-me sobre o que faziam seus pais. Onde viviam? Em que trabalhavam? Já trabalharam na cana?

- Do tempo que eu nasci, que eu vim saber quem era, meus pais sempre trabalhou de roça. Milho, feijão, meu pai tem um terreninho, tem quarenta tarefa de terra. Meu pai morou há dezesseis anos numa fazenda também. Depois da fazenda ele construiu o lugarzinho dele, é hoje o lugarzinho que a gente mora. Ele tem quarenta tarefas de terra plantada (Zerramos, 34 anos).

Quando postas em conjunto, salta à vista a quase homogeneidade na forma como se apresentam essas narrativas, o que poderia acenar para a tese da existência de um "exército de reserva”. Conquanto não nos pareça descabida essa consideração, ao menos como metáfora, ela induz uma leitura que obscurece pequenas diferenças sobre o modo como essas populações organizam suas estratégias de vida. No relato de Zerramos, fica evidente uma pequena mudança na trajetória de vida dos seus pais. "Zerramos" mora no sertão sergipano, onde não há cana-de-açúcar. Não se sabe ao certo se seus pais herdaram uma pe$\therefore$ quena propriedade e depois a ampliaram, ou se, de fato, conseguiram comprá-la. Mas ela alcança quarenta tarefas ${ }^{12}$ de terra. O principal produto cultivado nessa propriedade é o milho, tradicional na região. Assim, uma parte da $\dot{2}$ renda dos filhos que ainda estavam em casa é destinada à manutenção dessa lavoura, o que mostra como os indivíduos equacionam suas estratégias de reprodução em razão da atividade econômica considerada prioritária por eles. O trabalho externo dos membros dessa família, em outros setores de atividade, é regulado, por

${ }^{11}$ Os nomes doravante empregados são fictícios, para preservar o anonimato dos informantes.

12 Tarefa é uma unidade de medida que varia em diferentes estados; em Sergipe ela equivale a $3.052 \mathrm{~m}^{2}$. exemplo, em razão do sucesso ou infortúnio daquela lavoura.

Além disso, dão prova da manutenção de um conhecido fluxo migratório: são sertanejos que migram para o corte da cana. São os "corumbas", nos termos do já clássico estudo de Sigaud (1979). A análise de suas trajetórias laborais indica que alguns têm, no corte da cana, uma atividade subsidiária à agricultura que mantêm. Para esses, é o resultado dessa safra que regula o deslocamento, como no caso de Romeu, que possui uma pequena propriedade de terra onde cria alguns animais. Nossa conversa ocorreu justamente nessa pequena propriedade. Ele havia chegado do corte da cana na usina em que trabalhava e me contou que, sempre que sobra algum tempo, se dedica a cuidar da propriedade. Foi além, pois vejam o que ele me disse no momento em que conversávamos sobre seu dia de trabalho:

Entrevistador - Quem não tira a média, a usina bota para fora?

- Não, não. Aí só bota no período em que o cara tiver fichado, sabe. Mas, nesse caso que eu estou, eu estou provisório, não estou fichado. Eu estou com uns documento enjeitado aí para me aposentar. Aí eu não posso fichar, sabe? Aí eu trabalho provisório. E tem uma porção provisório.

Entrevistador - Mas foi você quem quis assim?

- Porque tá recebendo um seguro, sabe?

Entrevistador - E a usina permite?

- Rapaz, eles têm medo, tem e não tem, porque não tá ligando, né. E o povo quer. (grifo nosso)

É evidente o caráter precário e degradante dessa condição de trabalho. Todavia, no esforço por esmiuçar os significados contidos nessa passagem, depreende-se também um pequeno cálculo realizado pelo indivíduo. Uma vez que a usina faz uso de trabalhadores sem carteira assinada, portanto, um ilícito trabalhista, ele "aceita" esse tipo de situação ocupacional com um objetivo específico: aposentar-se como trabalhador rural. "Falsa consciência?" Ao que penso, isso evidencia, antes, a capacidade de agência do indivíduo para lidar com uma si- 
tuação que, de fato, é precária. O cálculo é feito por considerar que cinco anos a menos de trabalho são muito importantes para ele. Veja que, em seguida, ele revela que está recebendo seguro-desemprego; portanto, ainda tem a possibilidade de acumular momentaneamente duas fontes de renda.

Por fim, termina dizendo que "o povo quer”. Em termos sociológicos, sublinhar esse aspecto revela como essa teia de ações dá corpo a resultados diferentes, que não se resumem apenas à condição de uma suposta passividade dessas populações em relação à sua condição de trabalho, nem ao imobilismo frente às suas condições de vida. Ao mesmo tempo, adotar a hipótese contida na tese da "proletarização" da população campesina, a exemplo do que sugerira D’Incao (1984) nos anos oitenta, seria reduzir os termos do debate, ao não se considerar o modo como se estruturam as estratégias de sobrevivência dos indivíduos. O antigo suposto de populações passíveis de "proletarização" requeria operar com a dualidade "rural" versus "urbano", considerando o assalariamento um fenômeno exógeno àquelas "comunidades". Os atuais achados sugerem que a migração, por exemplo, pode servir tanto para reforçar a manutenção de sua condição de "assalariado", acentuando a segurança proporcionada pelos benefícios da Carteira de Trabalho "assinada", quanto para acumular recursos para outras atividades, a exemplo do cultivo de uma pequena roça.

Nesse contexto, não é de se estranhar que a iniciação no trabalho ocorra já desde o início da adolescência.

É desde cedo, nesse tempo não registrava carteira. Qualquer criança com idade de doze, treze anos já cortava cana.

Entrevistador - Mas você começou a trabalhar ajudando seu pai?

- Não, trabalhava eu e um irmão meu. Meu irmão mais velho.

Entrevistador - Com seu pai?

- Não, trabalhava só nós dois.

Entrevistador - Isso com quantos anos?
- Com doze anos de idade.

Entrevistador - E já trabalhava cortando cana?

- Com cana, doze anos de idade! A gente não chegamos nem a estudar! Não tinha como... A gente saímos da escola para trabalhar com cana. Só cana até hoje!

Entrevistador - Mas foi seu pai que incentivou vocês a trabalhar, ou foi vocês que decidiram?

- Ele falava assim: 'Meu fio, vocês é os dois hominho que já tá mais crescido, eu com muito filho'. Nesse tempo a coisa era mais difícil. 'Rapaz, vocês vão trabalhar, eu vou conversar com o feitorzinho ali do Cafuz (antigo engenho)'. Aí arranjou um serviço para a gente lá, a gente foi trabalhar. Aí a gente tava estudando, saímos da escola para trabalhar, porque o negócio é difícil né? (Eufrásio, 47 anos)

No excerto acima, percebe-se como a mão de obra das crianças vai sendo requisitada como complemento da renda familiar, seja em atividade própria ou externa. Mas esse processo obedece a um escalonamento: os mais novos acabam sendo preteridos em detrimento dos mais velhos. Na comparação com as idades apontadas como momento do início do trabalho, chamo a atenção para a demarcação simbólica da idade. Ela não parece obedecer a uma ordem cronológica que fixa uma determinada idade como indicador da aptidão ao trabalho. Ao invés, o que se tem é uma demarcação que associa a força física ao conhecimento das atividades requeridas na roça. Trata-se, portanto, de uma representação simbólica em torno do momento tido como propício ao início das atividades laborais. Ser "mais novo" ou "mais velho", nesse modo de escalonar o tempo, significa já ser considerado apto ao trabalho.

Há ainda outro marcador simbólico associado ao trabalho que nos leva a percebê-lo como um ritual de passagem para um suposto "amadurecimento". Nesse sentido, fazer-se "homem" passa pelo trabalho. Sobre esse ponto, as narrativas sugerem, em diferentes passagens, a constituição de uma ética do "bom trabalhador". Com razão, esse é um marcador identitário associado ao trabalho cujos efeitos transbordam para espaços extratrabalho. Ele é o cimento que reforça vínculos entre os indiví- 
duos e seus grupos de pertencimento, seja na comunidade ou no trabalho, como nos diz Woortmann (1990). Se, no varejo, em sua dimensão imediata, essa atividade laboral retira significado, no atacado, como trabalho em sentido mais amplo, forja-se a imagem do "bom trabalhador". Com o passar das narrativas, essa ética ficará ainda mais evidente, pois será fraseada como compromisso de "retidão", de "honestidade", de "honradez" e de "merecimento".

A família mostrou-se uma variável que exerce um peso considerável nas ações dos indivíduos. Ela se transforma em eixo que orienta e ampara a trajetória dos cortadores de cana. Aliás, o mais das vezes, as ações decorrem de uma conjunção com as estratégias familiares. Por vezes, em sua narrativa, o indivíduo apresenta sua trajetória de vida como refém de imperativos inegociáveis face à necessidade de sobrevivência. Com isso, deixa transparecer certo descaso, como se decisões importantes a exemplo de como e quando migrar - fossem tomadas sem nenhum planejamento. No entanto, à medida que a conversa flui e se passa a focalizar outros aspectos de sua vida, eis que surge uma rede complexa de elementos sobre os quais as decisões são tomadas.

Entrevistador - Você conversa com a família sobre onde vai trabalhar? Com quem você conversa?

- Eu boto na mente e vou. Eu converso, eu digo, até hoje eu digo. Nois conversa tudo. Eu nunca levei ela (a esposa), sabe? Nois tem sete meses de casado. Entrevistador - Em outra viagem que você for ela vai querer ir?

- Ela só veve me cobrando. Agora eu só levo ela assim sabe, chegar lá, passar uns dois meses, ver o movimento do lugar, porque eu não quero chegar lá, ver ela... Não, eu quero dar uma vida diferente, sabe? Eu não quero ver ela sofrendo nem nada.

Entrevistador - Não quer que ela se empregue nas usinas?

- Não, quero essa vida para ela não! Eu boto 'pocando’ aí já para arrumar as coisas dela, a minha... (Américo, 23 anos)

Também não é outro o significado da maneira como se estruturam as relações fami- liares em face das decisões tomadas a respeito do trabalho, no caso de Américo. Interessa-me, sobretudo, o arco de considerações a respeito do sentido de suas ações, que exprime clara influência da situação de "casado". Ao interromper a nomeação de uma situação que Américo não considera digna para a sua esposa - "porque eu não quero chegar lá, ver ela...”-, mas que ele conhece bem, eis que surge a forma de minorar tal situação: “Eu boto 'pocando' aí já para arrumar as coisas dela, a minha...”. O lastro que sustenta suas decisões vai na contramão do que parece sugerir o argumento que faz alusão a uma simples e direta "captura da subjetividade" desses sujeitos. Não é sem atritos que opera o receituário das empresas em busca de envolvimento do trabalhador.

Dissolver a representação feita pelos próprios indivíduos a respeito dos sentidos atribuídos às suas ações, julgando-as como tendo menor valor analítico, constitui uma armadilha metodológica. Ao contrário, quando invertemos os termos da relação na análise das formas de (re) produção social, encontramos, justamente, o elemento que pretendo sublinhar: a atribuição de significados diversos. É através deles que podemos observar os pequenos agenciamentos, a capacidade de dar uma orientação diversa ao que prevê o contexto social. Como nos lembra Marche (2012), sobretudo em contextos onde é dificultado o acesso às instâncias públicas de contestação, levar a sério a vida cotidiana, em sua dimensão infrapolítica, é outro modo de compreender como as experiências subjetivas dos atores pesam em mobilizações coletivas. Parece-me legítimo supor que pode haver um desnivelamento entre estruturas objetivas e práticas sociais. ${ }^{13}$

Encontro amparo nessa formulação em

${ }^{13}$ Nesse veio, descortina-se um fértil campo de investimentos analíticos, que indaga a dinâmica de atualização, ou rejeição, dos conteúdos disposicionais adquiridos e que se manifestam nas práticas sociais dos sujeitos, em alusão ao suposto bourdieusiano de atuação do habitus. Processos de socialização podem fornecer orientações normativas diversas, e mesmo contraditórias. Assim, compor-

tamentos idênticos podem ter sido concebidos em circunstâncias heterogêneas, e o inverso é igualmente verdadeiro (Cf. Barth, 1981). 
outros instigantes trabalhos que me antecederam e que procuraram apreender as estratégias construídas pelos indivíduos, famílias e grupos no enfretamento das situações de trabalho, na decisão de migrar e (ou) nas formas de resistência, a exemplo de Sigaud (1996), Scott (1985) e Menezes (2011).

Em outras ocasiões, especialmente na entressafra, podem variar bastante os recursos mobilizados para enfrentar a instabilidade ocupacional no corte de cana, tornando-se esse um momento privilegiado de observação, mormente acerca dos sentidos atribuídos e dos artifícios mobilizados para lidar com as situações adversas.

Entrevistador - No período da entressafra da cana, o que você faz? Em que trabalha?

- Não, eu 'tomo uma fuga'.

Entrevistador - Tomar fuga é dar um descanso?

- É. Pegar quatro, cinco meses. Se eu pegar seguro agora, eu vou passar quatro, cinco meses só lá, trabalhando na diária aqui, acolá.

Entrevistador - Na safra passada você fez isso?

- Em 2011, dia 10 de novembro, eu cheguei de Goiás. Daí não tinha seguro nem nada, daí eu gastei o dinheiro todinho na casa. Daí, 2012 já trabalhei quarenta dias na Guaxuma (usina em Alagoas), terminou em fevereiro lá. Daí pra lá, só fuga mesmo. Sete meses sossegado até começar aqui (em Sergipe).

Entrevistador - Então você não se preocupa em encarrilhar uma safra com a outra?

- Nada! Eu não penso nisso não. A vista de quem tem dez, quinze anos (que nem meu pai mesmo que tem mais de vinte anos de cana). Eu tô ligado mais ou menos como é. Porque seis meses de cana né fácil não! Quatro hora da manhã todo dia aí, botar comida ali na marmita... Aff! É rojão!

Entrevistador - Se não tirar o seguro é mais difícil?

- Nosso medo aqui tá sendo esse. Porque só vai fazer cinco meses dia oito, aí se ela não completar, nois tamo arrumado... Daí a chance de viajar é essa. (Américo, 23 anos)

Vê-se que, para enfrentar a instabilidade do emprego, os trabalhadores recorrem a estratégias diversas, não apenas no afã de manter alguma renda, como no esforço para recomporse, preparar-se para o "rojão” do corte da cana.
O recebimento do seguro-desemprego é, certamente, um norteador de condutas. Se, por um lado, as condições que tornam o trabalhador elegível para requerer assistência financeira nem sempre são atendidas, por outro, uma vez usuário de tal benefício, ele busca complementar a renda com trabalhos sem carteira assinada. Eis que surge o "bico", o trabalho na diária e o trabalho para "fornecedores", ou usinas que aceitam o empregado sem carteira assinada, como foi mencionado em outras entrevistas. A ausência de uma forma de proteção social mais abrangente, que minimize os efeitos da sazonalidade do trabalho na safra, motiva-os a buscar formas geralmente precárias de inserção ocupacional. A vivência dessa incerteza transparece no discurso dos indivíduos que, por sua vez, já pautam suas vidas em razão da variação na renda. Daí porque "tomar uma fuga” assume, no léxico dos trabalhadores, um significado de intervalo para o descanso do corpo. Fazer seguidas safras, mesmo que isso seja desejado, traz o ônus do extremo desgaste físico e mental, cujo horizonte é a morte ou a invalidez. Percebe-se, com os relatos, que essa informação não é desprezada pelos trabalhadores.

Não é de se estranhar que um tipo de trabalho sempre associado à condição de precariedade e a situações de extremo desgaste físico e mental assuma uma imagem extremamente negativa, mesmo para os cortadores de cana. Os vários relatos deixam avistar uma espécie de negação do trabalho, no sentido de que ele não seria fonte provedora de significados positivos para a vida dos indivíduos. Todavia, quando procuramos sondar os sentidos que permeiam essa prática de trabalho, o que se percebe é que existem outras imagens concorrentes atribuídas pelos indivíduos, as quais variam em decorrência de fatores tais como idade, tempo de trabalho, objetivos de vida, apenas para citar os mais palpitantes.

Como sugeri, a ideia da negatividade do trabalho no corte da cana é sentida no discurso dos entrevistados. A representação de seu 
trabalho está sempre associada a adjetivos tais como pesado, cansativo, ou ainda a expressões como "coisa de doido", de "desmantelado", entre outras. Ademais, e esse é um aspecto de extrema importância, eles próprios não se veem como "cortadores de cana", no sentido de reconhecer essa atividade como uma "profissão", nem como "migrantes". Ao contrário, costumam afirmar que não possuem uma "profissão", seja em razão da ausência de formação escolar, seja por reconhecerem como sua outra profissão que exerceram em algum momento de suas vidas. Qualquer que seja o motivo, nele se entrevê um forte indício de que a atividade atual que exercem não propicia elementos simbólicos positivos ao sabor dos quais se estruture um eixo para aflorar uma identidade de trabalho. O trabalho, ao invés de conferir reconhecimento, retira-o.

\footnotetext{
Entrevistador - Quando perguntam a sua profissão, o que você diz?

- Olha, minha profissão mesmo que eu tenho em minha carteira é padeiro. Chego nos lugar, minha profissão é padeiro. 'Hoje você tá fazendo o que?' Sou cortador de cana. E eu não tenho vergonha. O pessoal diz: 'É mesmo?’ Eu digo: olhe para minhas mãos [momento em que ele mostra as mãos calejadas]. (Justino, 28 anos)
}

Por certo, uma identidade profissional

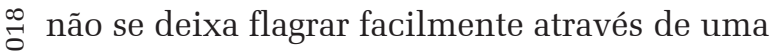
: pergunta assim formulada, que almeja ir direto ao ponto. Todavia, decidi incluí-la para perceber a reação de meus informantes. Até \& porque não seria essa a primeira vez em que eles teriam sido convidados a respondê-la, já que a pergunta está presente em questionários padronizados para obtenção de crédito, para \& abertura de conta em banco, em formulários के para acesso a programas do governo; ou seja, ela faz (ou fez) parte, em algum momento, da vida dessas pessoas.

Ademais, além de um possível problema semântico com o significado da palavra profissão ${ }^{14}$ - que de fato existe -, estou supondo ha-

${ }^{14}$ Embora formalmente constituída como uma profissão, institucionalizada e que, por isso mesmo, contempla, nos ver um ato intencional dos sujeitos em transmitir outra identidade, o que se manifesta em outros momentos da entrevista.

A linguagem constitui um espaço capaz de significar ou ressignificar os sentidos atribuídos à profissão - mas não somente a ela -, que, em geral, são negativos. Há um desafio sempre presente que remete à necessidade de sondar os significados conferidos a determinadas formas de expressão, sejam elas verbalizadas ou não (Cf. Santos Jr., 2013). Isso confere musculatura ao tipo de abordagem que desenvolvo, calcada na observação da percepção dos indivíduos, de maneira a refletir os elementos simbólicos que fundamentam o sentido da ação social.

Aqui também está o caráter contingente, ou multifacetado, de um modo particular de representação identitária (Dubar, 2005; Strauss, 1999). Ora, a mediação dos indivíduos face à imagem aparentemente negativa do trabalho expressa algum grau de reflexividade, que não se resume ao simples assentimento. Essa reflexividade irá diluir a negatividade por meio do recurso a elementos outros, oriundos de outros marcadores identitários e mais associados seja ao que advém dos resultados do trabalho, seja ao compromisso de ser um trabalhador "honrado". Assim, antes de identificar uma identidade, haveria um processo de negociação identitária que descortina a trama de interesses que mobilizam as ações dos indivíduos.

O efeito deletério dessa imagem associada ao trabalho que realizam se vincula a outro motivo presente no discurso dos indivíduos para justificar seu engajamento no corte da cana: a dimensão financeira. Eles são, por esse raciocínio, motivados a trabalhar no corte em razão do salário, da carteira assinada, o que constitui um benefício, quando comparado com as outras oportunidades de trabalho disponíveis na região

locais de trabalho, um quadro de hierarquia, competências e funções, essa dimensão profissional da identidade parece-me pouco efetiva como elemento de organização do significado e como motor de orientação a pautar a conduta dos indivíduos. Por isso mesmo, recorri ao conceito de identidades de trabalho como uma categoria de maior valor heurístico, por sua capacidade de melhor abarcar as especificidades dessa prática laboral. 
em que vivem. Sem esquecer, insisto que essas ações são tomadas em um contexto social carente de mecanismos de ancoragem social.

A manipulação dessa narrativa por parte do sujeito perfaz, como ordenação da atribuição de sentido às suas ações, um intenso jogo identitário. Decorre dessas narrativas uma imagem (ou imagens) que se pretende transmitir conscientemente ou não. Por seu turno, para revelá-la, é preciso recorrer às situações de interação, ou seja, o contexto da interação social cria a expectativa de comportamento, e o indivíduo a levará em consideração em sua ação.

Por razão semelhante, já o afirmara Menezes (2000), ao se questionar sobre um tipo de abordagem que reduz a representação identitária dos trabalhadores camponeses a um suposto imobilismo e passividade, ou, no polo contrário, tomando-os como rebeldes. Em seu estudo com trabalhadores migrantes da região da Mata Seca em Pernambuco, ela constata que as estratégias de ação - com relação à decisão de migrar, de mover uma ação trabalhista contra a usina, ou mesmo de deixar a usina - comportam algum cálculo de tomada de posição. Para Menezes (2000), mesmo a aceitação de situações que aparentemente indicam passividade precisa ser entendida dentro do conjunto de possibilidades naquele contexto. As decisões dos trabalhadores são feitas de modo ativo, como escolhas, variando conforme o leque das oportunidades que se apresentam naquele momento e conforme sua trajetória laboral e familiar.

A linguagem surge, então, como uma pista para sondar a atribuição de significados feita pelos trabalhadores às suas condições de vida e trabalho. O trabalho no corte da cana se apresenta esvaziado de significados "positivos". É o trabalho que, de alguma forma, deve ser escondido, mascarado, negado... Donde a experiência subjetiva assume o signo do sofrimento, do eminente desenraizamento físico e social, da exploração. É o que ocorre quando pergunto sobre como é trabalhar no corte de cana. Vejamos.
- Ah, é puxado... O ruim é a saudade, sabe? É quinze dias, um mês... É puxado, cansa. Mas depois o cara se acostuma, já era. O ruim é os primeiros dia. Tanto para o cara novato que nunca cortou... O ano que eu mais sofri na minha vida foi lá em São Paulo. Aí eu vi o ‘cão chupando manga', viu!?

Entrevistador - Sofreu por quê?

- Eu sofri de saudade e também não tinha costume. Até a mulher lá da minha rua disse: 'Vá não, você vai voltar no outro dia'. Aí eu disse: 'Apois, eu vou mostrar a você que eu não vou voltar no outro dia'. Porque quando eu tava lá na cana e lembrava do sofrimento que é no meu lugar, sem trabalhar nem nada... Ah! Eu não penso isso para minha vida não. Vou sofrer aqui, mas eu vou levar um dinheirinho para casa. Todo mês eu mandava dinheiro para minha família. (Américo, 23 anos, grifo nosso)

Mas, persevero, o sofrimento e a exploração não se reproduzem automaticamente sobre um ser inerte. Essas dimensões também são zonas de conflito e disputa. As ações dos indivíduos são parte nesse processo. Veja que "Américo", no segundo excerto, aponta para uma fonte motivadora externa. Ele diz: "Vou sofrer aqui, mas eu vou levar um dinheirinho para casa". Tem-se, aqui, um mecanismo que lhe permite atribuir significado à sua conduta frente a um trabalho aparentemente desprovido de valor positivo. Em termos sociológicos, o trabalho se torna, com isso, uma zona intermediária para os objetivos que são aludidos como tendo maior significado na vida dos indivíduos. Por essa via, negá-lo - de referência à identidade negada - representa um modo ativo de reagir às situações de exploração a que estão submetidos. Por essa mesma chave, pode-se entender por que outros símbolos de status - a exemplo da moto, da carteira de motorista, da casa etc. - não são meros "fetiches" de consumo. Eles representam o momento de afirmação dos indivíduos perante a comunidade, a devolução da imagem com a qual eles almejam ser reconhecidos, seja como "camponês", seja como "assalariado".

Em outas aspectos, tais como os significados atribuídos ao ato de migrar, também encontrei elementos que permitem afirmar quão 
diversa podem ser as estratégias de enfrentamento e sobrevivência (física e ocupacional) nesse tipo de trabalho. Assim, a profusão de vínculos feitos e refeitos ao longo da trajetória ocupacional desses trabalhadores dá o tom à dinâmica desse mercado de trabalho, com impactos na maneira como se formam as estratégias de manutenção dos vínculos, na forma como as famílias se estruturam, nos fluxos migratórios e nas formas de representação coletiva.

A inserção de Sergipe como demandante e ofertante de emprego no setor alterou circuitos migratórios regionais, especialmente com os estados vizinhos, Bahia e Alagoas. O que também vale para o caso do trânsito entre o Nordeste e o Sudeste, esse mais volumoso.

O fluxo migratório de trabalhadores sergipanos que se dirigem para o corte da cana em São Paulo apresenta alguma semelhança com outros contextos de migração, em outros estados. Nele, assumem grande importância as redes sociais. É por elas que irão passar as informações acerca das oportunidades de trabalho, do acolhimento e apresentação do trabalhador-migrante nas cidades de destino, configurando, assim, um circuito confiável que outros poderão fazer, aspecto também ressaltado por Fontes (2008). A decisão de migrar é, como se vê, equacionada pelos indivíduos em razão $\stackrel{\infty}{d}$ de suas estratégias de vida, ainda que, no dis$\stackrel{\circ}{\circ}$

, por vezes, ela assuma uma narrativa de "aventura” rumo ao desconhecido.

Entrevistador - Já migrou para outro estado?

- Sim, para São Paulo. Eu passei 10 meses em 2009, que foi na Moema [usina], em Orindiúva, e passei nove meses, que foi o ano passado, em Ibaté, na Zanin [usina]. Duas safras. Que a safra lá é longa, né?

Entrevistador - E como foi a contratação?

- A primeira que eu fui, em 2009, foi um rapaz que veio de lá para cá, enviado pela usina mesmo para aqui para Sergipe, Capela. Que ele era daqui de Capela. Ele foi daqui para lá, muito tempo, aí trabalhou na usina, virou cabo, de cabo foi para fiscal. Aí a usina enviou ele para aqui, para ele procurar o pessoal para ir para lá. Arrumar quatrocentas pessoas aqui. Aí ele arrumou, foi quatro ônibus que foi daqui para lá. Não chegou a quatrocentos não, foi trezentas e poucas pessoas daqui da região, entre Capela, Dores, Siriri. Todo lugar aqui ele foi procurando gente, foi se juntando e foi. A usina mandou o ônibus. Assim que ele arrumou o pessoal, mandou o pessoal de lá para cá para fichar, para sair daqui já fichado. Mandou ticket alimentação para nós ir na viagem.

Entrevistador - E depois, a outra viagem?

Aí eu voltei, trabalhei 2010 aqui (em Sergipe). Aí um colega meu ligou: 'lhe, a usina aqui em Ibaté é uma usina boa. Dá para ganhar dinheiro’.

Entrevistador - Um colega seu de lá?

- Não, é daqui mesmo, só que tava lá. 'Quer vim? Você topa vim para cá?’ Eu disse: 'Topo'. Eu tava casado, tinha pouco tempo, tava precisando juntar um dinheiro para mim construir uma casa, uma coisa assim ne? Tinha comprado uma moto, porque assim que eu cheguei de lá, em 2009, eu juntei um dinheiro, comprei uma Bros. Aí eu digo: 'Vou terminar de pagar ela'. Conversei com minha esposa, aí ela: 'Se você acha que é melhor para ganhar mais um dinheirinho, vamos'. Daí eu fui para lá, passei dois meses. Daí eu pedi para ela ir para lá, aí ela foi. Dessa vez, não foi alojamento, aí eu fui por minha conta. Eu nem sabia se quando chegasse lá eu ia conseguir vaga. Paguei ônibus, fui sozinho, cheguei lá conversei com esse colega meu que já tinha falado, fiquei com ele lá morando uma semana na casa dele. Aí ele disse: ‘Vamos lá na casa do rapaz?' Aí fomos, conversei com o turmeiro lá. Aí ele disse: 'Vou mandar sua carteira para a usina'. Aí ele viu a indicação, ne? Que eu era uma pessoa trabalhadeira, aí ele viu também a carteira. Pela quantidade de ficha. Se tiver umas ficha boa, aí vale a pena pegar a pessoa.

Entrevistador - O que é quantidade de ficha, é a experiência?

- É, é experiência. Aí a usina aceitou. Aí com cinco meses que eu tava lá eu chamei ela. Aí já tinha alugado uma casinha, tava eu e um colega meu. $A$ gente conseguiu vaga para mais uns colega daqui, aí foi mais três, aí ficou os quatro numa casa lá. Eu fiquei sozinho com minha esposa. Isso em 2011. Aí a usina pagava bem, dava cesta básica, você tinha uma cesta básica, dava para passar um mês a cesta básica.

Entrevistador - Você não quis ficar lá para a próxima safra?

- Não, porque o que eu combinei com a minha esposa foi aquilo: se eu conseguir juntar um dinheiro para construir minha casa, que ainda estou construindo, e conseguir tirar minha habilitação. Aí o 
tempo que eu fiquei lá, eu fui para uma autoescola [...].Aí, quando a safra acabou, o rapaz perguntou: 'Você quer ficar ou quer ir embora?' Eu digo: 'Não, eu quero ir embora'. Já tava com saudade já da minha família, já tinha mandado minha esposa ir embora. Aí recebi cinco meses de seguro, fiquei três meses parado sem trabalho, foi quando a Taquari chamou, aí fui para lá. (Josino, 27 anos, grifo nosso)

Essa longa narrativa dá provas da complexidade dos circuitos migratórios que são, à primeira vista, erráticos. ${ }^{15}$ Nesse exemplo, vimos que a decisão de migrar foi equacionada em família, além de ocorrer por intermédio de uma pessoa da comunidade, portanto, já conhecida. Na sua segunda viagem, já existem novos objetivos e a expectativa de auferir alguma poupança. Portanto, as estratégias de permanência vão sendo tecidas em razão das necessidades de sobrevivência. Assim, se a esposa for, é necessário encontrar emprego. Usualmente, já existe algum conhecido que pode fazer essa intermediação com as oportunidades de emprego na região. O mesmo vale para os períodos de entressafra: se estiver solteiro ou tiver deixado a família no local de origem, a probabilidade de retorno aumenta. Em outros casos, essa volta pode implicar custo desnecessário e dificuldade de manutenção, na ausência de oportunidades de emprego.

Essa forma de abordar a questão dos circuitos migratórios, que aqui são vistos como processos sociais, privilegiando-se a perspectiva que os indivíduos têm acerca deles, elege como grande desafio captar a forma como cada decisão é equacionada. O momento da partida ou do retorno se insere nas estratégias de vida dos indivíduos e é dependente de variáveis como o ciclo de vida, a situação civil, o planejamento financeiro. Não se trata, portanto, de um movimento irrefletido, sob o signo compulsório da exploração a que estão submetidos.

${ }^{15}$ Como o fluxo é sazonal, as bases de dados disponíveis tais como a PNAD e Censo, com cortes transversais, não nos permite flagrar o real dimensionamento desse trânsito de mão de obra. Para o caso da RAIS, existe a possibilidade de usar a RAIS Migra, que permite um corte longitudinal capaz de informar as trajetórias ocupacionais de cada trabalhador registrado no setor, descortinando novas possibilidades de investimentos analíticos.
Esse argumento está na raiz de análises clássicas, como as de Palmeira e Almeida (1977) e Martins (1986), entre outros que se recusam a interpretar o movimento migratório em apenas uma direção, seja pelo prisma dos fatores estruturais, seja pela suposição de que haja uma homogeneidade nos objetivos dos que migram.

Dessa forma, na existência de uma oportunidade de trabalho mais próxima do local de residência do trabalhador, para onde ele possa retornar uma vez ao mês, ainda que a renda auferida seja menor, ele tende a priorizar essa oportunidade ocupacional. Há bons motivos para crer que os circuitos regionais de migração, as políticas públicas de sedentarização dessa mão de obra, o incremento da mecanização da colheita, entre outros fatores, estão alterando o mapa das migrações para o Centro-Sul, o que ainda requer maiores investimentos analíticos. A possibilidade do emprego a curta distância reduz os riscos da viagem, possibilita manter o vínculo com a família e, talvez esse seja o aspecto mais importante: abre espaço para o desenvolvimento de outras estratégias de sobrevivência fora da atividade do corte da cana, seja um plano para a mudança de setor de atividade, seja a manutenção de pequena roça de onde provém o sustento.

Se a narrativa biográfica proposta pelo pesquisador e levada a cabo pelos sujeitos entrevistados é uma via de mão dupla, no sentido de que o ordenamento dos fatos é o resultado de um processo de edição de ambas as partes, ela é também uma importante ferramenta na análise do modo como se constituem as identidades. Como vimos, o caráter peculiar que assume a organização da vida, nas etapas que antecedem o ingresso no corte da cana, dá provas de uma característica que irá marcar os demais momentos, qual seja, a ambivalência. É assim que, a despeito da precariedade das condições de vida, o que poderia induzir a uma leitura cujo final já se conhece de antemão, os indivíduos mobilizam os recursos disponíveis de modo a oportunizar a condição que lhe pareça mais favorável. Essa capacidade de agência ex- 
pressa, por assim dizer, alguma capacidade de cálculo nas decisões que vão sendo tomadas ao longo da caminhada. Compreendê-las requer que saiamos da binaridade que supõe existir uma divisão drástica entre um modo de vida rural e outro urbano. O que não implica dizer que não haja distinções que demarquem diferenças a esse respeito. Assim, o caráter ambivalente do modo como se entrecruzam elementos nomeadamente "urbanos", a exemplo do assalariamento, e outros mais próprios à reprodução da "condição camponesa", como a manutenção de uma pequena roça de subsistência, parece marcar o quadro social dessas populações.

Nesse contexto, as identidades que emergem são, pela mesma razão, também ambivalentes. Se elas representam uma demarcação entre o "eu" e os "outros", é a mecânica dessa distinção que informa como agem os indivíduos. Com isso, ainda que a migração favoreça o "desenraizamento" dos trabalhadores, ela também nutre diferentes experiências de trabalho que lhes permite uma visão de perspectiva na comparação com realidades distintas. É o momento em que nasce a percepção de injustiça, catalizadora de ações coletivas. Essas, por seu turno, na maioria dos casos, assumem uma forma ligeiramente distinta do conflito aberto, com atores pronunciados em primeira pessoa. Ao contrá-

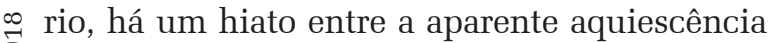
กิ e a contestação das situações que marcam o trabalho no corte da cana, que se resolve quando se descortina a miríade das pequenas ações de resistência. É aqui também que se enraíza a o recurso a uma identidade de trabalho "negada". Como havia dito, o que se recusa é a face pre¿. cária do trabalho. Não por desconhecê-la, mas ¿ porque ela não confere aos trabalhadores o reके conhecimento preterido. Esvaziado de sentido positivo, não sendo o trabalho no corte da cana reconhecido como "profissão", os indivíduos se afirmam em outro eixo: através dos elementos advindos de sua "condição de assalariado", especialmente os bens materiais adquiridos com a sua renda e valorizados na comunidade em que vivem.
Ao fim e ao cabo, cabe ainda ressaltar que o recurso à linguagem dos direitos também é devedor da forma como se percebe e como se estrutura o conflito. Por conseguinte, não é a gradação entre um maior ou menor conhecimento dos direitos que informa a maneira como eles serão mobilizados a seu favor, mas o conteúdo das relações sociais que se estabelecem em cada contexto e que se assenta em elementos outros, a exemplo da honra, da reciprocidade, só para citar os mais recorrentes.

\section{APONTAMENTOS À GUISA DE CONCLUSÃO}

Decerto que isso não esgota o leque de questões que nos ajudam a entender a complexa trama sobre como se constroem identidades a partir da experiência do trabalho e, através desse processo, compreender os agenciamentos que são feitos pelos sujeitos no afã de interpretar a realidade que os circunda. O ir e vir das formas de nominar as práticas de trabalho, que carrega uma pretensão de ação, mas que também se deixa influir em razão do contexto, traz a marca das disputas sobre diferentes narrativas e práticas dos sujeitos, que emergem de forma variada e por caminhos diversos. Como disse um dos entrevistados ao falar sobre o processo, sempre obscuro, de aferição da produtividade dos trabalhadores: "com toda sabedoria deles aí, né?!”. Deveríamos desprezar esse "senso comum" que encampa uma rede de resistências contra os desmandos dos patrões? Ainda que isso signifique operar na margem do possível?

Ainda nesse registro, já há um aporte considerável de literatura a respeito do modo como se estabelece a dramaturgia das resistências miúdas, que eventualmente emergem como manifestações coletivas, mas não raro contestam os meios usuais de protesto via mobilização sindical (Cf. Menezes; Cover, 2016), o que sugere a fertilidade analítica de se trabalhar na contraposição entre formas de dominação e modos de resistência. 
Nessa forma de argumentar há, por certo, um aparente jogo de escalas. No entanto, a meu juízo, não se trata de ceder à vertigem do individual, do que seria excepcional. Ao invés, o esforço constitutivo foi o de buscar diferentes meios de formalização causal dos fenômenos sociais aqui analisados. É nesse veio que flui ampla literatura, em termos de teoria social, que vem enfrentando o desafio de recompor a equação elementar da tradição sociológica no que tange à relação entre estrutura e agência, como sugerem Veráne e Vandenberghe (2016) e Lahire (2001). Aqui, vimos como práticas sociais atualizam formas diversas de (re) produção social, o que significa dizer que há aceitação, mas também rejeição de elementos presentes em processos de socialização dos quais os sujeitos são partícipes.

De igual modo, à luz das transformações recentes nas relações econômicas e de trabalho no campo, não parece interessante seguir formulando novas questões de análise a partir do pressuposto contido na separação entre um modo de vida rural e um modo de vida urbano. Mesmo supondo que a lógica da racionalidade urbana avance sobre o campo, levando consigo uma mudança na gestão da atividade econômica e nos usos do trabalho, esse processo não é isento de atritos e fissuras. Ao invés, em lugar da suposta diluição das diferenças, esse processo pode ocasionar justamente o oposto, reforçar identidades assentadas no pertencimento a uma localidade, cuja compreensão depende menos de uma ideia de "ruralidade", que se apega a critérios descritivos, e mais ao modo como se combinam os interesses dos indivíduos e grupos na relação com o contexto e com suas trajetórias de vida, como já havia sugerido Carneiro (1998) e Menezes e Malagodi (2009).

Ao fim e ao cabo, a capacidade para agir de outro modo revela que as ações dos indivíduos não são meros reflexos das estruturas em que estão inseridos. O esforço de abordagens como essa à qual recorri tem como alvo os processos que empoderam, esclarecem e auxiliam os indivíduos a tomar decisões. Se pudermos falar em "estruturas profundas" (Lévi-Strauss, 1978) e o seu efeito duradouro no conteúdo disposicional dos indivíduos, parece válido supor também que a contingência da vida cotidiana deixa divisar o que os motiva a investir, ou resistir, às diferentes experiências recebidas do quadro social mais amplo em que vivem e trabalham. Para que tomemos um caso como exemplo, a gestão dos rendimentos auferidos no corte da cana não parece decorrer de um simples acoplamento a uma lógica que os induz a produzir cada vez mais, ${ }^{16}$ uma vez que imperativos outros - cabendo mencionar a vida familiar, a necessidade de "tomar uma fuga" ${ }^{17}$ e a manutenção de uma atividade econômica subsidiária na pequena lavoura - expõem lógicas muitas vezes conflitantes com aquela orientação. É nessa câmara escura das escolhas e formas de se posicionar frente aos desafios da sobrevivência que se pode encontrar a dinâmica desses agenciamentos.

Recebido para publicação em 27 de setembro 2016 Recebido em 19 de maio de 2018

\section{REFERÊNCIAS}

ALEXANDER, J. O novo movimento teórico. Revista brasileira de Ciências sociais, v. 2, n. 4, p. 5-28, jun. 1987. Disponível em: <http://www.anpocs.org.br/portal/ publicacoes/rbcs_00_04/rbcs04_01.htm $>$. Acesso em: 10 out. 2014.

ALMEIDA, M. da G. S. de. Nordeste açucareiro: desafios num processo de vir-a-ser capitalista. Aracaju: Universidade Federal de Sergipe, 1993. 321 p.

ALVES, F. Processo de trabalho e danos à saúde dos cortadores de cana. INTERFACEHS: revista de gestão integrada em saúde do trabalho e meio ambiente, São Paulo, v. 3, n. 2, abr./ago. 2008. Disponível em: $\leq$ http:// www3.sp.senac.br/hotsites/blogs/InterfacEHS/vol-3-2ano-2008-2/>. Acesso em: 4 maio 2013.

ARCHER, M. S. Structure, agency and the internal conversation. Cambridge: Cambridge University Press, 2003. 384 p.

Making our way through the world: human reflexivity and social mobility. Cambridge: Cambridge University Press, 2007. 353 p.

${ }^{16}$ A composição dos salários, para o caso dos cortadores de cana, é variável em razão do pagamento por produção, cuja forma de aferição é sempre tema de conflitos entre os trabalhadores e as usinas.

${ }^{17}$ No léxico nativo, designa a necessidade de intercalar períodos de trabalho com períodos de descanso na entressafra.

.


The reflexive imperative in the late modernity. New York: Cambridge University Press, 2012. 354 p.

BARTH, F. Process and form in social life. London: Routledge \& Kegan Paul, 1981. 239 p.

BOLTANSKI, L.; THÉVENOT, L, De la Justification: les économies de la grandeur. Paris: Éditions Gallimard, 1991. $203 \mathrm{p}$.

CARNEIRO, M. J. Ruralidade: novas identidades em construção. Estudos sociedade e agricultura, p. 53-75, 1998. Disponível em: <https://revistaesa.com/ojs/index. php/esa/article/view/135 $\geq$. Acesso em: 26 set. 2010.

CERTEAU, M. de. A invenção do cotidiano: artes de fazer. Petrópolis: Vozes, 2014. 320 p. v. 1.

COLEMAN. J. S. Microfoundations and macrosocial behavior. In: ALEXANDER, J. C. et al. (Ed.). The micromacro link. California: University of California Press, 1987. p. 153-176.

D’INCAO, M. C. A questão do bóia-fria. São Paulo: Brasiliense, 1984.96 p.

DUBAR, C. A socialização: construção das identidades sociais e profissionais. São Paulo: Martins Fontes, 2005. $376 \mathrm{p}$.

ESTUDO das condições e ambientes de trabalho na produção de cana-de-açúcar no Estado de Sergipe. Aracaju: Fundacentro: MPT, 2012.

FONSECA, C. Classe e a recusa etnográfica. In: FONSECA, C.; BRITES, J. (Org.). Etnografias da participação. Santa Cruz do Sul: EDUNISC, 2006. 355 p.

FONTES, P. Um Nordeste em São Paulo: trabalhadores migrantes em São Miguel Paulista (1945-66). Rio de Janeiro: Ed. FGV, 2008. 366 p.

GARCIA JR. A. R. O sul: caminho do roçado: estratégias de reprodução camponesa e transformação social. São Paulo: Marco Zero; Brasília: Editora Universidade de Brasília,1989. 285 p.

GIDDENS, A. Central problems in social theory: action, structure and contradiction in social analysis. Berkeley: University of California Press, 1979. 294 p.

GUIMARAES, N. A. Por uma Sociologia do desemprego. Rev. Bras. Ci. Soc., v. 17, n. 50, p. 104-121, 2002. Disponível em: $\quad<$ http://www.scielo.br/scielo.php?pid=S0102$092002000300007 \&$ script $=$ sci_abstract\&tlng $=$ pt $\geq$. ${ }_{0}^{\infty}$ Acesso em: 7 jun. 2014.

. Desemprego e procura de trabalho: alguns $\dot{\circ}$ desafios. Revista ciências do trabalho, n. 7, p. 21-35, abr. 2017. Disponível em: $\leq$ https://rct.dieese.org.br/index.php/ rct/article/view/116>. Acesso em: 2 maio 2018.

INSTITUTO BRASILEIRO DE GEOGRAFIA E \& ESTATÍSTICA. [20--]. Disponível em: <www.ibge.gov. br>. Acesso em: 5 jun. 2018.

$\infty$ LAHIRE, B. Catégorisations et logiques individuelles: les $\dot{2}$ obstacles à une sociologie des variations intraindividuelles.

क Cahiers internationaux de sociologie, n. 110, p. 59-81, 2001.

$\infty$ Doi:10.3917/cis.110.0059. Disponível em: $\leq$ https://www.

\& cairn.info/revue-cahiers-internationaux-de-sociologie-

- 2001-1-page-59.html >. Acesso em: 8 set. 2017.

$>$ LÉVI-STRAUSS, C. Mito e significado. Lisboa: Edições 70, ô $1978.81 \mathrm{p}$.

LOPES, J. S. L. O vapor do diabo. São Paulo: Paz e Terra, 1978.220 p.

Ii MARCHE, G. Why infrapolitics matters? Revue française d'études américaines, n. 131, p. 3-18, 2012. Doi 10.3917/ rfea.131.0003. Disponível em: <https://www.cairn.info/ Z revue-francaise-d-etudes-americaines-2012-1-page-3. htm>. Acesso em: 7 jul. 2018.
MARTINS, J. de S. Não há terra para plantar neste verão: o cerco das terras indígenas e das terras de trabalho no renascimento político do campo. Petrópolis: Vozes, 1986. $112 \mathrm{p}$.

MENEZES, M. A. de. Experiência social e identidades: trabalhadores migrantes na plantation canavieira. História oral, n. 3, p. 49-68, 2000. Disponível em: < http://revista.historiaoral. org.br/index.php?journal $=$ rho\&page $=$ issue\&op $=$ view \& path $\% 5 \mathrm{~B} \% 5 \mathrm{D}=6$ \& path $\% 5 \mathrm{~B} \% 5 \mathrm{D}=$ show Toc $>$. Acesso em: 4 fev. 2011.

Redes e enredos nas trilhas dos migrantes: um estudo de famílias de camponeses-migrantes. Rio de Janeiro: Relume Dumará; João Pessoa: EDUFPB, 2002. $249 \mathrm{p}$

Estratégias, táticas e resistências no cotidiano dos canaviais. In: MENEZES, M. A. de; GODOI, E. P. G. (Org.). Mobilidades, redes sociais e trabalho. São Paulo: Annablume; Brasília: CNPq, 2011. 241 p.

MENEZES, M. A.; COVER, M. Movimentos "espontâneos": a resistência dos trabalhadores migrantes nos canaviais. Cadernos CRH, Salvador, v. 29, n. 76, p.133-148, abr. 2016. Disponível em: <http://www.scielo.br/scielo. php? $\quad$ pid $=$ S0103-49792016000100133\&script $=$ sci abstract\&tlng $=p t>$. Acesso em: 3 out. 2017.

MENEZES, M. A.; MALAGODI, E. Campina grande: os camponeses como atores sociais: a perspectiva da autonomia e da resistência. Campina Grande: Projeto IPODE: CNPq, 2009.

MORAES, M. A. F. D. de. A influência dos sindicatos nos salários do setor sucroalcooleiro. Rev. Econ. Polit., São Paulo, v. 31, n. 3, p. 471-492, set. 2011. Disponível em: <http:// www.scielo.br/scielo.php?script $=$ sci_arttext\&pid $=$ S0101$31572011000300009 \& \operatorname{lng}=$ en $\& \mathrm{nrm}=\overline{\mathrm{i}} \mathrm{so}>$. Acesso em: 29 jun. 2018.

NOVAES, J. R. P. Idas e vindas, disparidades e conexões regionais: um estudo sobre o trabalho temporário de nordestinos na safra da cana paulista. In: NOVAES, J. R.; ALVES, F. (Org.). Migrantes: trabalho e trabalhadores no complexo agroindustrial canavieiro (os heróis do agronegócio brasileiro). São Carlos: EDUFSCAR, 2007. $314 \mathrm{p}$.

ORTNER, S. Resistance and the problem of ethnographic refusal. Comparative studies in society and history, v. 37, n. 1, p. 173-193, 1995. Disponível em: < https://www.jstor. org/stable/179382? seq=1\# page scan tab contents $>$. Acesso em: 23 abr. 2014

PAIS, J. M. Vida cotidiana: enigmas e revelações. São Paulo: Cortez, 2003. 271 p.

PALMEIRA, M.; ALMEIDA, A. W. B. A invenção da migração: projeto emprego e mudança sócio-econômica no Nordeste. In: RELATÓRIO de Pesquisa. Rio de Janeiro: Museu Nacional, UFRJ, 1977. Mimeografado.

PASSOS SOBRINHO, J. M. dos. História econômica de Sergipe (1850-1930). 1983. 158 p. Dissertação (Mestrado em Economia) - Instituto de Economia, Universidade de Campinas, Campinas, 1983.

SANTOS JR., J. Sob o véu da linguagem: desafios e impasses no estudo das identidades. Indagatio didactica, v. 5, n. 2, p. 507-516, out. 2013. Disponível em: < http:// revistas.ua.pt/index.php/ID/article/view/2470>. Acesso em: 20 jul. 2018.

$\mathrm{Na}$ trama das identidades: práticas sociais e imagens do trabalho no corte de cana. São Paulo: Annablume, 2017. 287 p.

SCOTT, J. Weapons of the weak: everyday forms of peasant resistance. New Haven: Yale University, 1985. 422 p.

SILVA, M. A. de M. Destino e trajetória de camponeses migrantes. In: ENCONTRO NACIONAL DE ESTUDOS POPULACIONAIS, 8., 1992, São Paulo. Anais... São 
Paulo: [S.n.], 1992. v. 3. Disponível em: < http://www.abep. org.br/ abeporgb/publicacoes/index.php/anais/article/ view/611/591>. Acesso em: 28 jan. 2017.

. Errantes do fim do século. São Paulo: Fundação Editora da UNESP, 1999. $370 \mathrm{p}$.

Expropriação da terra, violência e migração: camponeses maranhenses no corte da cana em São Paulo. Cadernos CERU, v. 19, n. 1, série 2, p. 165-180, jun. 2008. Disponível em: <https://www.revistas.usp.br/ceru/article/ view/11851/13628>. Acesso em: 12 fev. 2011.

SIGAUD, L. Os clandestinos e os direitos: estudo sobre trabalhadores da cana-de-açúcar de Pernambuco. São Paulo: Duas Cidades, 1979. 260 p.

. Direito e coerção moral no mundo dos engenhos. Revista estudos históricos, Rio de Janeiro, v. 9, n. 18, p. 361388, dez. 1996. Disponível em: <http://bibliotecadigital. fgv.br/ojs/index.php/reh/article/view/2030>. Acesso em: 29 jul. 2010.
STRAUSS, A. Espelhos e máscaras: a busca de identidade. São Paulo: Edusp, 1999. 177 p.

THOMAZ JR., A. Por trás dos canaviais: os nós da cana. São Paulo: Annablume: Fapesp, 2002. 388 p.

THOMPSON, E. P. A miséria da teoria ou um planetário de erros: uma crítica ao pensamento de Althusser. Rio de Janeiro: Zahar Editores, 1981. 228 p.

TURNER, J. H. et al. A emergência da teoria sociológica. São Paulo: Vozes, 2016. 486 p. (Coleção Sociologia).

VÉRAN, J.-F; VANDENBERGHE, F. Novas sociologias: um exercício de teoria comparativa. In:_. Além do habitus: teoria social pós-bourdieusiana. Rio de Janeiro: 7Letras, 2016. $214 \mathrm{p}$

WOORTMANN, K. Migração, família e campensinato. Revista brasileira de estudos de população, v. 7, n. 1, p. 35-53, jan./jun. 1990. Disponível em: < https://www.rebep. org.br/revista/article/view/546>. Acesso em: 1 fev. 2012. 


\section{THE FORGOTTEN DIMENSION: the question of agency in sugarcane harvest work}

Jaime Santos Júnior

By fixing the analytical proposal in the links that unite the work experience and the process of identity construction, we sought to catch the small but subjectively important forms of measurement and calculation involved in the strategies of action by workers of sugar cane harvest. In spite of precariousness of the social context, the results show that the meanings attributed to work by the subjects allow us to figure out fissures and resistances which denote the agency of individuals and this is far from an image in which they are mere spectators of history.

Keywords: Work. Identity. Agency. Sugarcane sector. Sergipe.

\section{LA DIMENSION OUBLIÉE: la question de l'agence dans les travaux de récolte de la canne}

Jaime Santos Júnior

En fixant la proposition d'analyse dans les liens qui unissent l'expérience de travail et le processus de construction identitaire, nous avons cherché à capture les petits, mais subjectivement importantes formes de mesure et de calcul impliqués dans les stratégies d'action par les travailleurs de la récolte de la canne à sucre. En dépit de la précarité du contexte social, les résultats montrent que les significations attribuées au travail par les sujets nous permettent de comprendre les fissures et resistences qui dénotent l'agence des individus. Distant d'une image dans laquelle ils sont de simples spectateurs de l'histoire.

Mots-CLÉs: Travail. Identité. Agence. L'industrie de l'alcool et de sucre. Sergipe. 